Postgirad. med. J. (1966) 42, 527.

\title{
LYMPHOBLASTIC ALEUKAEMIC LEUKAEMIA WITH BONE CHANGES IN AN ADULT
}

\author{
M.R.C.P. (Edin.) \\ Chief of Department of Internal Medicine
}

T. A. Don Michael, M.B., M.R.C.P.(Lond.)

\author{
B. Parvaresh, M.D. \\ Physician
}

C. Z. BIDARI, M.D.
Senior House Physician
ACUTE lymphatic leukaemia is a disease predominantly affecting children and bone changes have been described in association with it (Baty and Vogt, 1935), (Silverman, 1948), (Willson, 1959). The disease however and more remarkably bone changes in association with it, are extremely rare in adults (Dameshek and Gunz, 1964).

\section{Case Report}

A 26-year-old male patient was admitted on the 6th July, 1963 with fever, rigors, a sore throat and generalized aches and pains. He recovered after a course of tetracycline. On 27th August of the same year the patient was readmitted with fever, rigors, generalized aches and pains and icterus was observed. The liver was moderately enlarged and tender but neither spleen nor lymph nodes were enlarged. Although the serum bilirubin was slightly raised $(1.25 \mathrm{mg} . / 100 \mathrm{ml}$.), there was no bile in the urine. Nausea, vomiting and epigastric pain with intense lethargy, dominated the clinical picture. Coombs test was negative as were the other tests to exclude a haemolytic process. Liver function tests were normal and the serum bilirubin reverted to normal a few days after admission. On the 19th September and until the 10th December, anaemia (Haemoglobin 7.5-10 g./100 ml.) and neutropenia $(800-1200 / \mathrm{cu} . \mathrm{mm}$.) was noted although the platelet and reticulocyte counts were normal. Steroid therapy, blood transfusions and penicillin were started and the total white cell count and polymorph differential count gradually increased although the anaemia persisted.

Investigations: The red cells were slightly hypochromic with anisocytosis and poikilocytosis. Bone marrow biopsy performed on 10th November revealed a highly cellular marrow with over $90 \%$ of leucocyticlelements showing abnormal morphology and about $50 \%$ of lymphoblasts, the megakaryocytes and erythroid elements being drastically reduced. (Figs. $2 \& 3$ ). Radiology of the skeleton revealed multiple osteolytic lesions without surrounding bony reaction, scattered throughout the skull (Fig. 1), ribs, iliac bones and long bone extremities. The spine was normal. Serum protein and paper electrophoresic revealed no abnormality and there was no Bence Jones proteosuria. The serum calcium was raised (12.2 mg./ $100 \mathrm{ml}$., serum phosphorous $4.4 \mathrm{mg} . / 100 \mathrm{ml}$.) but both acid and alkaline phosphatase levels were normal.
Progress: The patient began to experience severe bone pain especially in the lower limbs and there was a persistent bone tenderness and a fluctuating pyrexia. On this regime, the peripheral blood picture improved; Hb. 11 g./100 ml. WBC 4,400/cu. mm., normal differential count with no other abnormalities (on 22nd December, 1964). Intense tiredness, bone pain and progressive cachexia however, were marked features and the patient was severely depressed. His dose of prednisone which had been $60 \mathrm{mg}$. daily, was increased up to $120 \mathrm{mg}$. on 17th March, 1964 and full doses of 6-mercaptopurine were started hoping to achieve a remission. Despite these measures and intermittent blood transfusions the patient gradually went downhill and died on the 1st April, 1964. A post-mortem examination was not obtainable.

\section{Discussion}

Leukaemia represents an abnormal proliferation of one of the white cell forming elements (Dameshek and Gunz, 1964). Bone changes in association with leukaemia have been divided into four types (a) a transverse band or line of reduced density at the

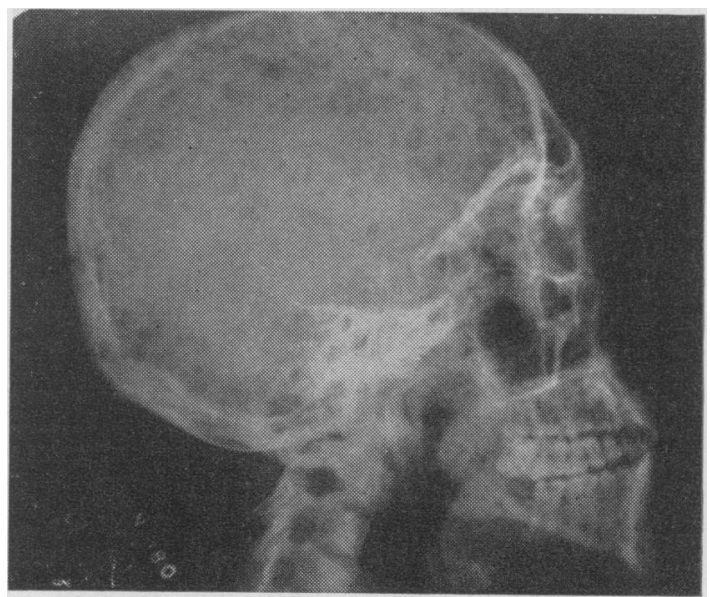

Fig. 1.-The skull X-ray shows multiple osteolytic areas. 


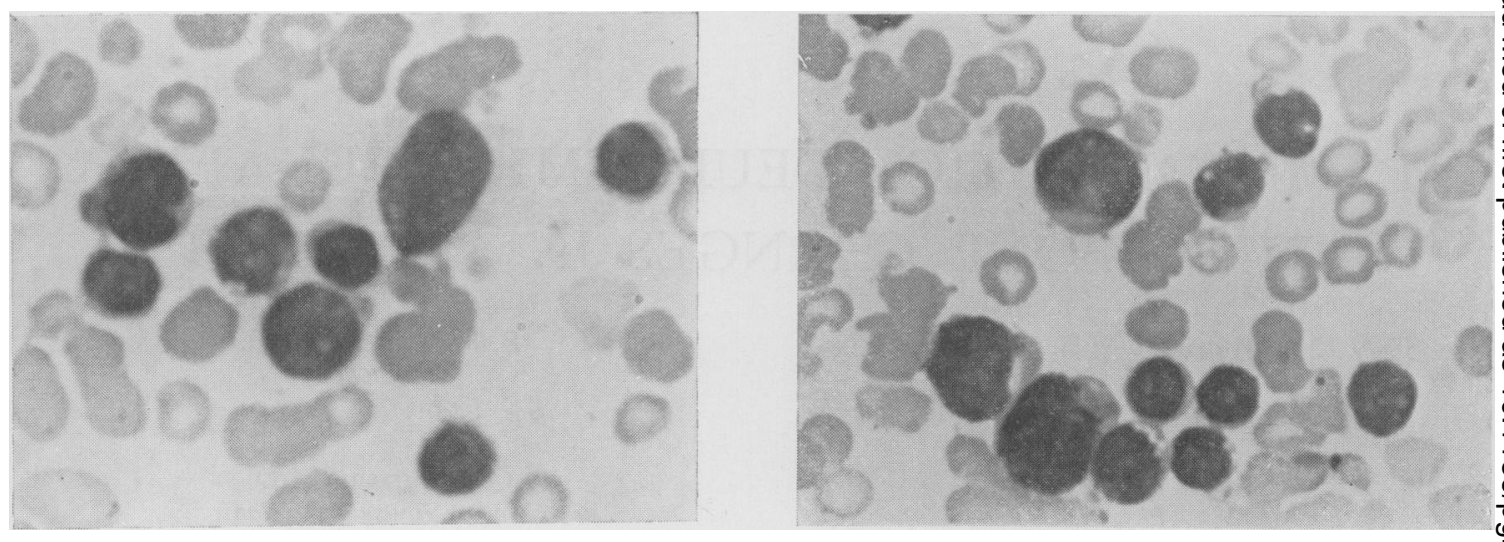

FIGS. 2 \& 3.-The slides represent smears taken of bone marrow and show the typical changes of lymphoblastic leukaemia.

ends of long bones (b) osteolytic lesions (c) osteosclerosis (d) periosteal reaction and new bone formation (Moseley, 1964). In cases with bone involvement, osteolytic lesions of the diffuse or circumscribed type are present in $59 \%$ of cases (Willson, 1959). Bone involvement in leukaemia is rare in adults $(8-10 \%)$ in comparison with children $(60-70 \%)$. When it does occur in adults the large majority do so in chronic lymphatic leukaemia, although it is thought that some of these are cases of lymphosarcoma, (Jaffe, 1958). Bone changes in lymphoblastoma have a similar incidence and age distribution to those of acute lymphatic leukaemia (Jaffe, 1958). They are thus excessively rare in adults, and in highly malignant lesions. The case described could equally be regarded as one of lymphoblastoma. In the absence of an autopsy it is only possible to state that the bone marrow was involved. The radiological changes and their location resembled myelomatosis in the case described though there was no evidence pointing towards it. The great majority of acute lymphatic leukaemias occur in children and are rare in adults. The occurrence of selective agranulocytosis and anaemia without pancytopenia is unusual as was the presence of hepatic tenderness, which is not said to occur in the absence of heart failure. From the view point of treatment although steroids probably affected the white cell count, there was no real benefit from their use. Remissions have been claimed on heroic doses of steroids (50-100 mg.) prednisone daily (Dubois-Ferriere, Zumstein, Bouvier, Kalaci, Sorg, Vauther and Hausser, 1956; Hill, Marshall and Falco, 1956; Granville, Rubio, Unugur, Schulman, and Dameshek, 1958). These workers felt that smaller doses merely caused subjective improvement and reduced the tendency to bleed; it is felt that side effects follow their use and smaller doses (150 mgm. prednisone) 권 are effective (Dameshek and Gunz, 1964). Similaro claims have been made for 6-mercaptopurine in full doses (Burchenal, Murphy, Ellison, Sykes, Tan, $\rightarrow$ Leone, Karnofky, Craver, Dargeon and Rhoads, 1953; Hayhoe, 1955, Whitelaw, Moffat, Perry and Beck, 1956). The value of the two drugs $\overrightarrow{-}$ administered together has not been fully assesse however. High dose irradiation and autologou transplantation of bone marrow has achieved $\frac{9}{4}$. "take" in a large proportion of cases but homologous transplants are mostly rejected. In no case, however, has recovery taken place (Dameshek and Gunz, 1964).

\section{Summary}

A patient is described who presented with several rare features; the combination of osteolytic bone changes in an adult suffering from subleukaemic acute lymphoblastic leukaemia presenting as an unexplained agranulocytosis and anaemia. The $\frac{\dot{0}}{3}$ clinical course and treatment are reviewed.

My thanks are due to Dr. Ansari our pathologist $\delta$ and the pathological department of the Postgraduate Medical School of London, also to Dr. Rouhani for $\mathrm{O}$ permission to publish the case.

\section{REFERENATS}

Baty, J. M., and VoGt, E. C. (1935): Bone Changes of Leukaemia in Children, Amer. J. Roentgenol, $\mathbb{O}$ 34, 3190.

BURCHENHAL, J. H., IMURPHY, M. L., Ellison, R. R., SYKeS, M. P., TAN, T. C., LeONE, L. A., KARNOFSKY, D. A., Craver, L. F., DARGEON, H. W., and RHOADS, C. P. (1963): Clinical Evaluation of a New Antimetabolite 6-mercaptopurine, in the Treat- $\stackrel{?}{+}$ ment of Leukaemia and Allied Disonders, Blood, 8,

965.
DAMESHEK, W., and Gunz, F. (1964): Leukaemia, 2nd $\stackrel{\mathbb{D}}{\circ}$ edit. New York: Grune and Stratton. 
Dubois-Ferriere, H., Zumstein, P., Bouvier, C., KalaCi, J., Sorg, D., Vauther, J., and Hausser, A. (1956): Cortisone à Doses Massives et 7-mercaptopurine dans le Traitment des Leucemies Aigues de L'adulte: possibilite d'obtenir des Remissions Successives, Praxis, 45, 93.

Granville, N. B., Rubio, F., Unugur, A., Schulman, E., and DAMESHEK, W. (1958): Treatment of Acute Leukaemia in Adults with Massive Doses of Prednisone and Prednisolone, New Engl. J. Med., 259, 207.

HAYHOE, F. J. G. (1955): 6-mercaptopurine in Acute Leukaemia, Lancet, ii, 903.

Hill, I. N., Marshall, G. J., and Falco, D. J. (1956): Massive Prednisone and Prednisolone Therapy in Leukaemia and Lymphomas in Adult, J. Amer. Geriat. Soc., 4, 627.
Moseley, J. E. (1963): Bone Changes in Hematologic Disorders. New York: Grune and Stratton.

Whitelaw, D. M., Moffatt, R. G., Perry, W. H., and BECK, R. E., (1956): Acute Leukaemia in Adults Treated with 6-mercaptopurine, Canad. med. Ass. J., 74, 423.

Silverman, F. N. (1948): Skeletal Lesions in Leukeamia: Clinical and Rontgenographic Observations in 103 Infants and Children, with Review of Literature, Amer. J. Roentgenol, 59, 819.

Willson, J. K. (1959): The Bone Lesions of Childhood Leukemia : a Survey of 140 cases, Radiology, 72, 672 . 